\title{
Behaviour of laying curve in Babcock-380 brown commercial layers in Kelantan, Malaysia
}

\author{
M R Amin ${ }^{* 1}$ and S A Nawawi ${ }^{2}$ \\ ${ }^{I}$ Faculty of Agro Based Industry ${ }^{2}$ Faculty of Earth Science \\ University Malaysia Kelantan (Campus Jeli), 17600 Jeli, Kelantan, Malaysia \\ ruhulaminbau1961@gmail.com or ruhulamin@umk.edu.my
}

\begin{abstract}
Commercial layers start laying at 18-20 weeks of age and continues until 72 weeks under cost-effective operation. Age of the hens, mortality rate, feed and environmental conditions determine the persistancy of production as reflected in the laying curve. In this experiment laying performance of 10000 hen-housed Babcock-380 brown commercial layers housed in Kelantan, Malaysia was assessed in mathematical model using hen-house and hen-day measurements. It revealed that hens reached at peak lay at 21 weeks of age and maintained a stability until 44 weeks. Birds egg laying performance gradually declined with progress in age till 80 weeks. $Y=35176.99-397.374 \mathrm{~A}+5.065 \mathrm{~F}$ gave the best fitted regression line (adj $R^{2}=0.905$ ) for hen-housed egg production per week ( $A=$ age of hens in week and $F=K g$ feed consumed/day). A $87.5 \%$ of the total variation in hen-housed egg production could be explained only by age of hens but when feed consumption was added in the model age and feed consumption together explained $90.5 \%$ variabilty. For every week advancement in hen's age (week) a decrease of 0.039 eggs/hen/day was predicted (adj $R^{2}=83.8 \%$ ). In this 10000 henhoused flock mortality/culling averaged at 14.82/week.

Key words: Babcock-380, hen-house egg production, hen-day egg production, mathematical model, laying curve
\end{abstract}

\section{Introduction}

Commercial egg production with hybrid chicken is a very delicate bioentrepreneurship all over the world. There are currently only few number of poultry breeding companies in the world owned pure lines to make available grand parent and parent stocks to the breeder farm. Modern strains of hybrid layers are produced by the local breeder farm/hatcheries using parent stocks. Lohman (white and brown), H\&N white [Singh et al., 2009, Silverside et al., 2012], Hy-Line (white and brown), Shaver (Anonym1, 2013), Starcross, Babcock (Chowdhury et al., 2002, Durraniet al., 2012), Hisex (durrani, 2012) are the commonest hybrid strains of layer chicken. According to Verma and Singh (1997) $87.33 \%$ contribution to gross return in layer enterprize comes from eggs alone. Egg production by the hens in the laying cycle is influenced by manifold factors such as strain, feed, survival rate and health of hens, management practices, age at point-of-lay, age at peak-of-lay (Durrani et al., 2012). In a given flock egg production in a particular day of laying cycle depends on number of hens in the cohort, stage of laying phase, hen health, feed, environmental condition such as temperature, humidity, light, molting etc. Modern hybrid layers start laying at 18-20 weeks of age and continue until 72 weeks or little longer cost-effectively (Amin and Hamidi, 2013). Determination of laying performance on individual hen basis involves huge labour and cost. Therefore, flock efficiency is the most preferential approach for measuring laying efficiency. 'Hen house egg production' and 'hen day egg production'are the two widely used method of measuring flock laying efficiency (Singh and Kumar, 1994). Stage of laying is a great determinant of number of eggs laid in a given day in the laying cycle and therefore, it contributes greatly in the shape of laying curve. In ideal condition, standard laying curve can predict the number of eggs to be laid out of a given flock size. Amin (2012) demonstrated an incipient hen-day part laying curve with fitted quadraic equation $\left(\mathrm{Y}=0.0483 \mathrm{t}^{2}-3.904\right.$, $\mathrm{t}=$ age of hen in day; $\left.\mathrm{R}^{2}=0.807, \mathrm{p}<0.001\right)$ for Babcock brown 380 layers in Kelantan, Malaysia. Zattar and Nofal (2009) showed that relationship between egg number and variable age of hens in weeks can be best represented in polynomial curve for Memourah $\left(0.868 \leq \operatorname{adj} R^{2} \leq 1.0\right)$ and Montazah $\left(0.992 \leq \operatorname{adj} R^{2} \leq 1.0\right)$, the two locally developed layer strain of chicken in Egypt. Atta et al. (2010) concluded that Wood equation (1967) can be used with sufficient precision to predict whole cycle laying performance based on part egg production record in Hyline W98 and Lohman SLS hybrid layers.Nevertheless, standard fitted regression line on laying performance for common commercial hybrid layersis still inadequately available in literature. The present investigation, therefore, aims at developing a standard mathematical model for Babcock brown 380 layer hens in Kelantan, Malaysia along with some other related measurements.

\section{Materials and Methods}

Data for this study were extracted from Taklimat Project Ternakan Ayam Penelor Tertutup - a government private ownership layer farm in Kuala Balah, Kelantan, Malaysia. The flock of Babcock- 380 brown layers consisted of 10,000 pullets placed in the laying house at the age of 17 weeks in 2010.The pullets started laying in the following week and continued until 80 weeks of age. From 17-20 weeks of age daily egg 
production quickly rose from 60 to 6300 and then became almost stable and took a regular shape of trend.That's why 21 weeks of age was considered as the begining for analysis of data.Furthermore, eggs laid until 20 weeks were of smaller size and showed higher frequency of abnormality. Daily records were kept on number of hens $\mathrm{died} /$ culled, number of eggs laid, amount of feed consumed on flock basis.Birds were provided with commercial layer mash diet at the rate of $400 \mathrm{~kg}$ to $850 \mathrm{~kg}$ /day during first week of the placement in the laying house and thereafter $900 \mathrm{~kg}$ to $1100 \mathrm{~kg} /$ day until last day. Variation in the amount of feed provided was independent of the number of hens in the house rather was depended on voluntary intake by the hens. In order for quantifying the efficiency of the layers, the following measurements were made (Amin, 2012)

i. Hen house egg production per week $(\mathrm{HHEPPW})=\frac{\text { No of eggs laid in a given week }}{\text { No of hens at the begining of the week }}$

ii. Hen housed egg production per cent per day (HHEPPD) $=\frac{\text { No of eggs laid in a given day }}{\text { No of hens on that day }} \times 100$

Hen housed egg production per week indicates number of eggs laid per bird in a given week calculated based on the number of hens placed at the begining of the week. So mortality/culling of hens within the period affects HHEPPW. On the contrary, hen housed egg production per cent per day (HHEPPD) expresses average laying performance of a hen in the flock in a particular day based on the exact number of hens exists on the particular day. So mortality or culling does not affect HHEPPD but it includes birds that did not lay for any reason.

Statistical analyses were accomplished with the help of SPSS 11.5 statistical software. HHEPPW was compared between a duration of every 3 months using one way ANOVA and then Tukeys test was performed for multiple comparison (Kaps and Lamberson, 2009). So each 3 months laying duration (from 6 month to 20 month) was splitted into equal 5 periods. The HHEPPW and HHEPPD were regressed against age of hens in week to see the pattern of changes of egg production with progress of age. Age of hens and feed consumption were incorporated in the mathematical model to estimate their contribution in egg production.

\section{Results and Discussion}

Egg Production: HHEPPW was compared between periods of every 3 month from 6 to 20 months of age (2180 weeks) of the hens. Age group (month) differed significantly $(p<0.05)$ in HHEPPW (Table 1). HHEPPD was compared between same periods but expressed in weeks and periods differed significantly $(p<0.05)$ (Table 2$)$. Ten thousands hen-housed layers laid 60341.66 eggs per week during 6-8 months of age and upon gradual declination in the number of eggs per week HHEPPW averaged at 50165.83 at the age of 18-20 months. HHEPPW was found to be significantly decreased with the progress of age in months of the hens giving a pattern of 6-8 months $=9-11$ months $>12-14$ months $=15-17$ months $>18-20$ months (Table 1 ).

Table 1 : Mean HHEPPW in varying ages of hens hens

Table 2 : Mean HHEPPD in varying ages of

\begin{tabular}{|l|l|}
\hline $\begin{array}{l}\text { Age of hens } \\
\text { (month) }\end{array}$ & Mean HHEPPW \\
\hline $6-8$ & $60341.66^{\mathrm{a}}$ \\
\hline $9-11$ & $58312.50^{\mathrm{a}}$ \\
\hline $12-14$ & $48000.00^{\mathrm{b}}$ \\
\hline $15-17$ & $44450.00^{\mathrm{b}}$ \\
\hline $18-20$ & $39725.00^{\mathrm{c}}$ \\
\hline $\begin{array}{l}\text { Overall } \\
\text { HHEPPW }\end{array}$ & 50165.83 \\
\hline
\end{tabular}

\begin{tabular}{|l|l|}
\hline $\begin{array}{l}\text { Age of hens } \\
\text { (week) }\end{array}$ & Mean HHEPPD \\
\hline $21-32$ & $6.0743^{\mathrm{a}}$ \\
\hline $33-44$ & $5.9352^{\mathrm{a}}$ \\
\hline $45-56$ & $5.0166^{\mathrm{b}}$ \\
\hline $57-68$ & $4.7153^{\mathrm{c}}$ \\
\hline $69-80$ & $4.3094^{\mathrm{d}}$ \\
\hline Overall HHEPPD & 5.2102 \\
\hline
\end{tabular}

Table 3 : Mean difference (Tukey's test) of HHEPPW between months

\begin{tabular}{|c|c|c|c|}
\hline \multicolumn{2}{|c|}{$\begin{array}{l}\text { Age of hens (month) } \\
\text { I, J }\end{array}$} & \multirow[t]{2}{*}{$\begin{array}{l}\text { Mean difference } \\
(\mathrm{I}-\mathrm{J})\end{array}$} & \multirow[t]{2}{*}{ Sig } \\
\hline I & $\mathrm{J}$ & & \\
\hline \multirow[t]{4}{*}{$6-8$} & $9-11$ & 2029.16 & .482 \\
\hline & $12-14$ & $12341.66\left(^{*}\right)$ & .000 \\
\hline & $15-17$ & $15891.66(*)$ & .000 \\
\hline & $18-20$ & $20616.66(*)$ & .000 \\
\hline \multirow[t]{4}{*}{$9-11$} & $6-8$ & -2029.16 & .482 \\
\hline & $12-14$ & $10312.50\left(^{*}\right)$ & .000 \\
\hline & $15-17$ & $13862.50(*)$ & .000 \\
\hline & $18-20$ & $18587.50(*)$ & .000 \\
\hline \multirow[t]{2}{*}{$12-14$} & $6-8$ & $-12341.66\left(^{*}\right)$ & .000 \\
\hline & $9-11$ & $-10312.50(*)$ & .000 \\
\hline
\end{tabular}




\begin{tabular}{|l|l|r|r|}
\cline { 2 - 4 } & $15-17$ & $3550.00(*)$ & .045 \\
\cline { 2 - 4 } & $18-20$ & $8275.00(*)$ & .000 \\
\hline \multirow{5}{*}{$15-17$} & $6-8$ & $-15891.67(*)$ & .000 \\
\cline { 2 - 4 } & $9-11$ & $-13862.50(*)$ & .000 \\
\cline { 2 - 4 } & $12-14$ & $-3550.00(*)$ & .045 \\
\cline { 2 - 4 } & $18-20$ & $4725.00(*)$ & .003 \\
\hline $18-20$ & $6-8$ & $-20616.67(*)$ & .000 \\
\cline { 2 - 4 } & $9-11$ & $-18587.50(*)$ & .000 \\
\cline { 2 - 4 } & $12-14$ & $-8275.00(*)$ & .000 \\
\cline { 2 - 4 } & $15-17$ & $-4725.00(*)$ & .003 \\
\hline
\end{tabular}

$(*)$, significant

Table 2 and Table 4 show that HHEPPD during 21-32 weeks did not differ ( $p>0.05)$ from that in 33-44 weeks means that HHEPPD was almost stable in these two periods.It shows that during 21-32 weeks average egg production per hen per week figured at 6.0743 which is point of peak lay and then steadily declined until 80 weeks. The flock kept hold peak production until 44 weeks started from 21 st week. HHEPPW and HHEPPD behaved similarly ( Fig 1 and Fig 2) during these periods which means that mortality/culling of hens did not affect egg production during early phase of laying since they are very few in number (Fig 5).The HHEPPD of 45 - 56 weeks and 57- 68 weeks also did not vary significanty ( $p>0.05$ ). The regression lines in Fig 1 and Fig 2 represent HHEPPW and HHEPPD of the hens respectively from 21 to 80 weeks. Fig 1 explains that an increase of 1 week in layer's age will decrease 457.4 eggs/week in a hen-housed flock of 10000 hens. A $87.5 \%$ of the total variation of the HHEPPW can be explained by the variation in the age (week). The value of Pearson Correlation, -0.935 shows that there is exist strong negative relationship between HHEPPW with age (Table 5). It is also supported by value of Pearson Correlation. Fig 2 suggests that for every week advancement in hen's age a decrease of $0.039 \mathrm{egg} / \mathrm{hen} /$ day does happen. The coefficient of determination $\left(\mathrm{R}^{2}\right)$ indicates that $83.8 \%$ of the total variation of the HHEPPD is explained by the variation in the age (week). Not many literature are available to compare present results. However, Zatter and Nofal (2009) demonstrated that polynomial regression line suits best to predict the relationship between age of hens in week and the number of eggs laid in Mamourah layers which is $Y=-2.743+3.248 x-0.545 x^{2}+0.048 x^{3}-0.002 x^{4}+5.81266 E-05 x^{5}-5.84542 E-07 x$ ${ }^{6}(\mathrm{p}<0.001)$. Hen-day percentage of the same strain was predicted by the same authors with the equation $\mathrm{Y}=$ $101.468+133.369 \mathrm{x}-36.033 \mathrm{x}^{2}+3.997 \mathrm{x}^{3}-0.1604 \mathrm{x}^{4}(\mathrm{p}<0.001)$.

Durrani (2012) reported age of point-of-lay and age of peak-of-lay of Hisex and Babcock strains of layers in Pakistan to be 116.81, 136.80 and195.26, 204.40 days respectively (strain difference significant, $\mathrm{p}<0.05$ ) which are in line with the present findings. Current study reveals that peak production did exist between 148 and 308 days (21-44 weeks) and birds started laying at 17 weeks. Peak egg production percent (calculated from Table 2) obtained in this investigation was 86.78 where as Durrani (2012) showed 91.85 and92.72 percent peak egg production in Hisex and Babcock layers. This discrepancy might be because peak egg production in terms of HHEPPD was reported in this case by a mean for a period of 3 months in which HHEPPD was in decreasing trend. Zatter and Nofal (2009) showed that egg number and hen day percentage were significantly $(\mathrm{p}<0.001)$ increased with the advancement of age to reach peak at the 5th week of laying and reached at peak at 14th week of production in Mamourah and Silver Montazah local strain in Egypt. In the current study laying was started at 17th week and reached peak at 21st week which is in good agreement with the results of Zatter and Nofal (2009) although strains are different. Age at point-of-lay, age at peak-of-lay and persistency of egg production determine mostly the shape of the laying curve.

Table 4. Mean difference (Tukey's test) of HHEPPD between weeks

\begin{tabular}{|c|c|c|c|}
\hline \multicolumn{2}{|c|}{$\begin{array}{l}\text { Age of hens (weeks) } \\
\text { I, J }\end{array}$} & \multirow[t]{2}{*}{$\begin{array}{l}\text { Mean } \\
\text { difference (I-J) }\end{array}$} & \multirow[t]{2}{*}{ Sig } \\
\hline I & $\mathrm{J}$ & & \\
\hline \multirow[t]{4}{*}{$21-32$} & $33-44$ & .1392 & .791 \\
\hline & $45-56$ & $1.0577(*)$ & .000 \\
\hline & 57-68 & $1.3591\left(^{*}\right)$ & .000 \\
\hline & $69-80$ & $1.7649(*)$ & .000 \\
\hline \multirow[t]{3}{*}{$33-44$} & $21-32$ & -.1392 & .791 \\
\hline & $45-56$ & $.9186\left(^{*}\right)$ & .000 \\
\hline & $57-68$ & $\left.1.2199^{* *}\right)$ & .000 \\
\hline \multirow[b]{2}{*}{$45-56$} & $69-80$ & $1.6258(*)$ & .000 \\
\hline & $21-32$ & $-1.0577(*)$ & .000 \\
\hline
\end{tabular}




\begin{tabular}{|l|l|r|r|}
\cline { 2 - 4 } & $33-44$ & $-.9186\left(^{*}\right)$ & .000 \\
\cline { 2 - 4 } & $57-68$ & .3013 & .119 \\
\cline { 2 - 4 } & $69-80$ & $.7072\left(^{*}\right)$ & .000 \\
\hline $57-68$ & $21-32$ & $-1.3591\left(^{*}\right)$ & .000 \\
\cline { 2 - 4 } & $33-44$ & $-1.2199\left(^{*}\right)$ & .000 \\
\cline { 2 - 4 } & $45-56$ & -.3013 & .119 \\
\cline { 2 - 4 } & $69-80$ & $.4058\left(^{*}\right)$ & .014 \\
\hline $69-80$ & $21-32$ & $-1.7649\left(^{*}\right)$ & .000 \\
\cline { 2 - 4 } & $33-44$ & $-1.6258\left(^{*}\right)$ & .000 \\
\cline { 2 - 4 } & $45-56$ & $-.7072\left(^{*}\right)$ & .000 \\
\cline { 2 - 4 } & $57-68$ & $-.4058\left(^{*}\right)$ & .014 \\
\hline
\end{tabular}

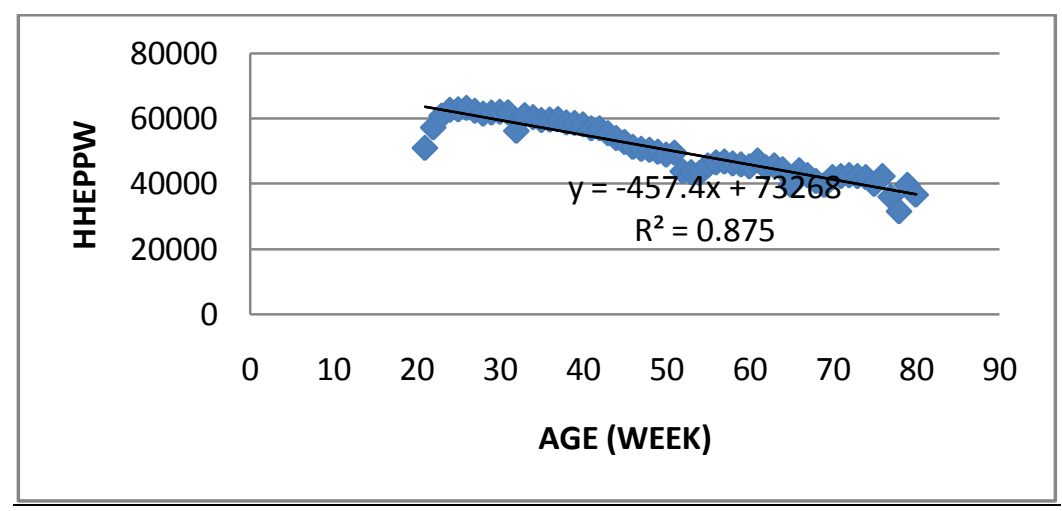

Fig 1. HHEPPW against age of hens in week

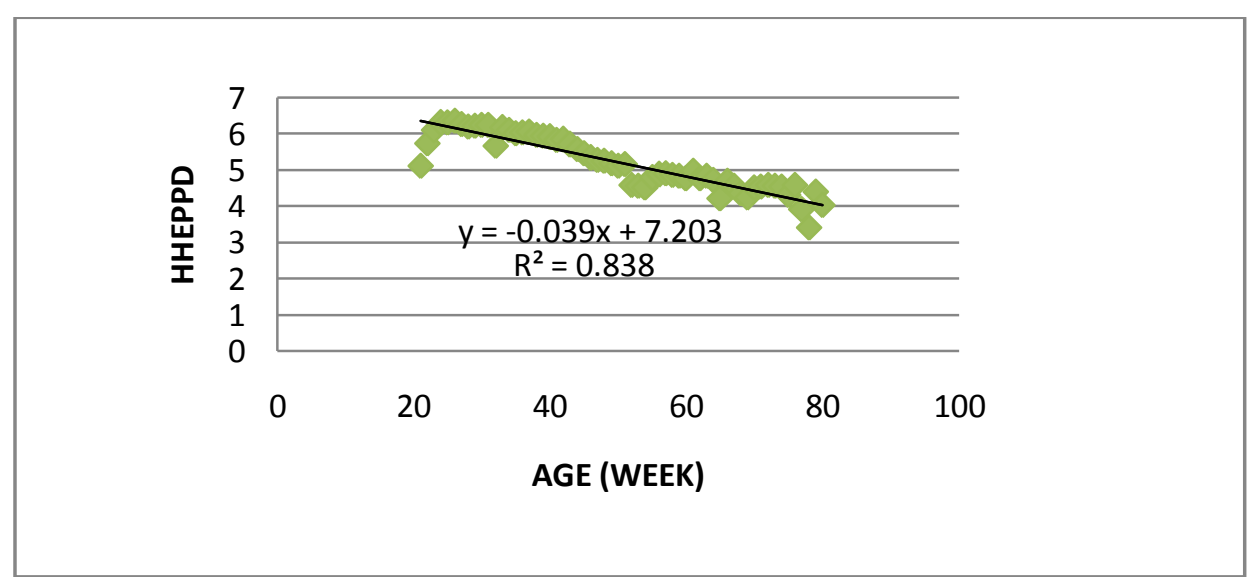

Fig 2. HHEPPD against age of hen in week

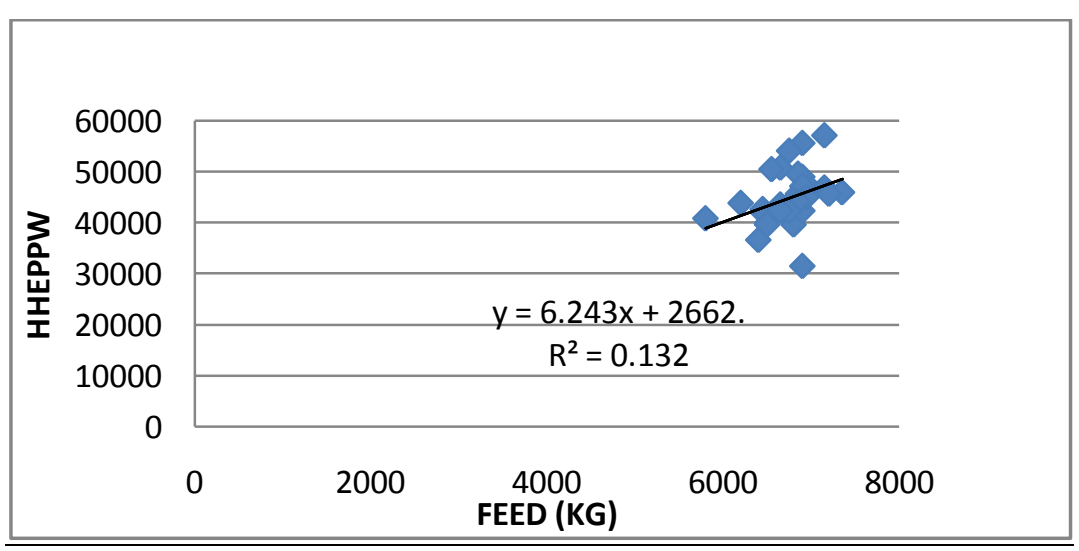

Fig 3. Relationship of feed consumed with HHEPPW 
Table 5. Pearson correlation matrix of HHEPPW with age of hen (week) and feed consumed $(\mathrm{kg})$

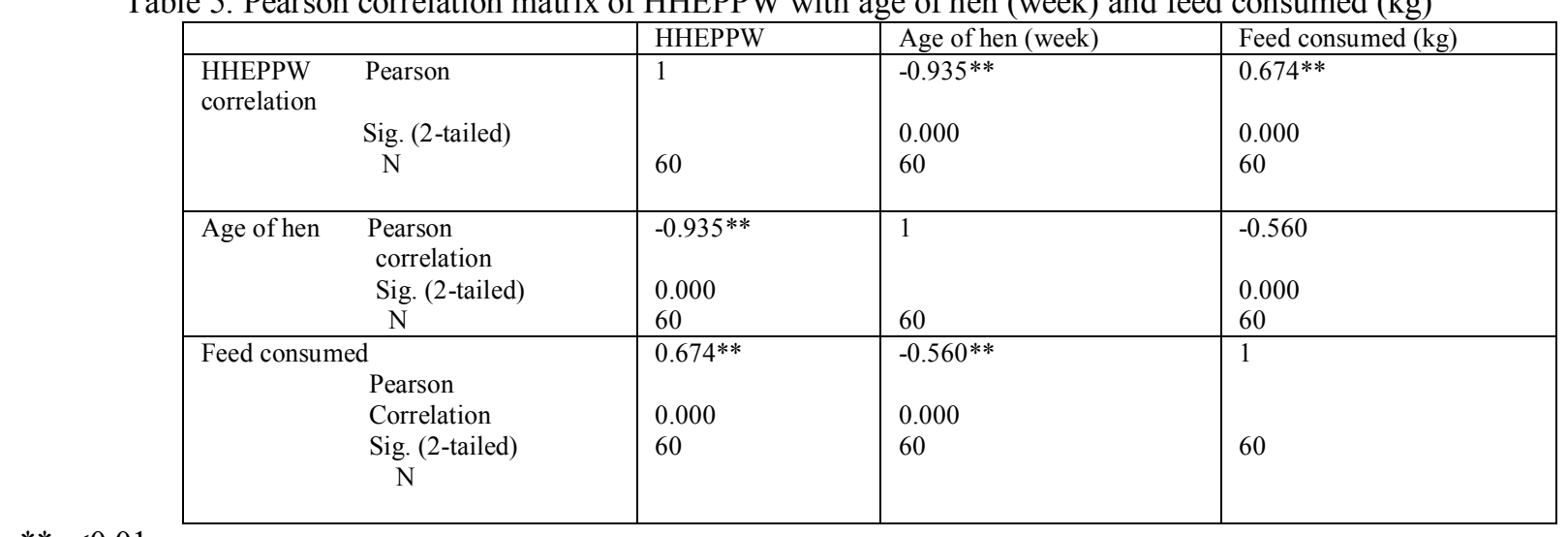

$* * \mathrm{p}<0.01$

Feed consumption: Some 900 to $1100 \mathrm{~kg}$ feed was provided daily to the hen after first week of placement although birds had access of 400-850 kg feed/day during first week. Fig. 4 shows that relationship between feed intake and HHEPPD is positive but week. Variation in the feed intake might be due to some variation in the house temperature and humidity ( Atta, 2010). However, feed intake positively and significantly $(\mathrm{p}<0.001)$ affected HHEPPW (Table 5) and HHEPPD (Fig 4).

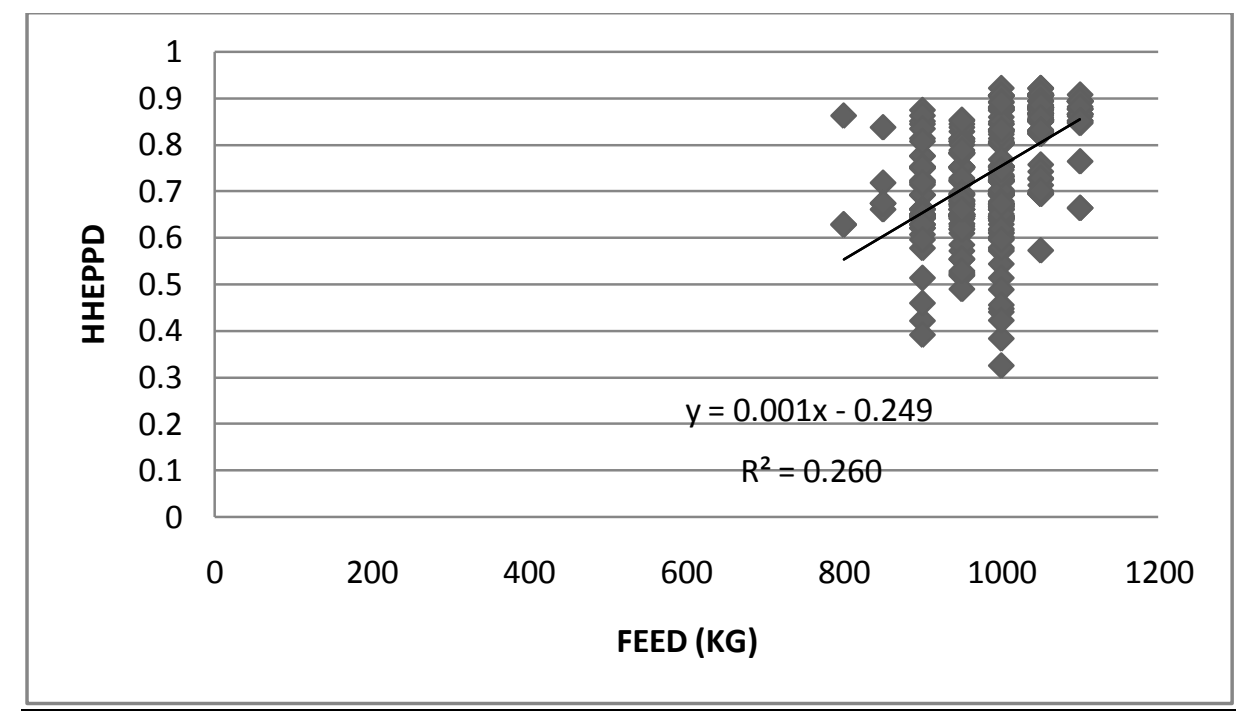

Fig 4. Relationship of feed consumed with HHEPPD

Coefficients of multiple determination and estimated value of $\boldsymbol{\beta}$ : When amount of feed consumed and age of the hens were considered as contributing factors of HHEPPW in the regression model it was able to explain about $91 \%$ of the variability (Table 6 ). The regression equation appears to be very useful for making prediction since the value of $\mathrm{R}^{2}$ is close to 1 .

Table 7 shows the estimated value of $\beta, t$ and level of significance of the contributors in HHEPPW. Both the independent variables such as amount of feed provided daily and age of the hens (month) contributed significantly $(\mathrm{p}<0.001)$ in HHEPPW. The standard fitted multiple regression equation becomes $H H E P P W=$ $35176.99-397.374 A+5.065 F$ where $\mathrm{A}$ and $\mathrm{F}$ stands for age of the hens in month and daily feed conssumption in $\mathrm{kg}$.It tells us that age in month linearly and negatively influenced HHEPPW but daily feed intake positively influenced egg production measured in terms of HHEPPW and the $t$ values for both the independent factors are highly significant $(\mathrm{p}<0.001)$.

Table 6. Coefficient of multiple determination

\begin{tabular}{|l|l|l|l|}
\hline Model & R & R square & Adj R square \\
\hline 1 & $0.953 \mathrm{a}$ & 0.908 & 0.905 \\
\hline
\end{tabular}


Table 7. Estimated value of $\beta$

\begin{tabular}{|c|c|c|c|c|c|}
\hline Model & \multicolumn{2}{|c|}{ Unstandardized Coefficients } & $\begin{array}{l}\text { Standardized } \\
\text { Coefficients }\end{array}$ & $\mathrm{t}$ & Sig. \\
\hline & B & SE & Beta & & \\
\hline 1 (constant) & 35176.990 & 8464.270 & & 4.156 & 0.000 \\
\hline Age (month) & -397.374 & 23.684 & -0.813 & -16.778 & 0.000 \\
\hline Feed (kg) & 5.065 & 1.117 & 0.220 & 4.535 & 0.000 \\
\hline
\end{tabular}

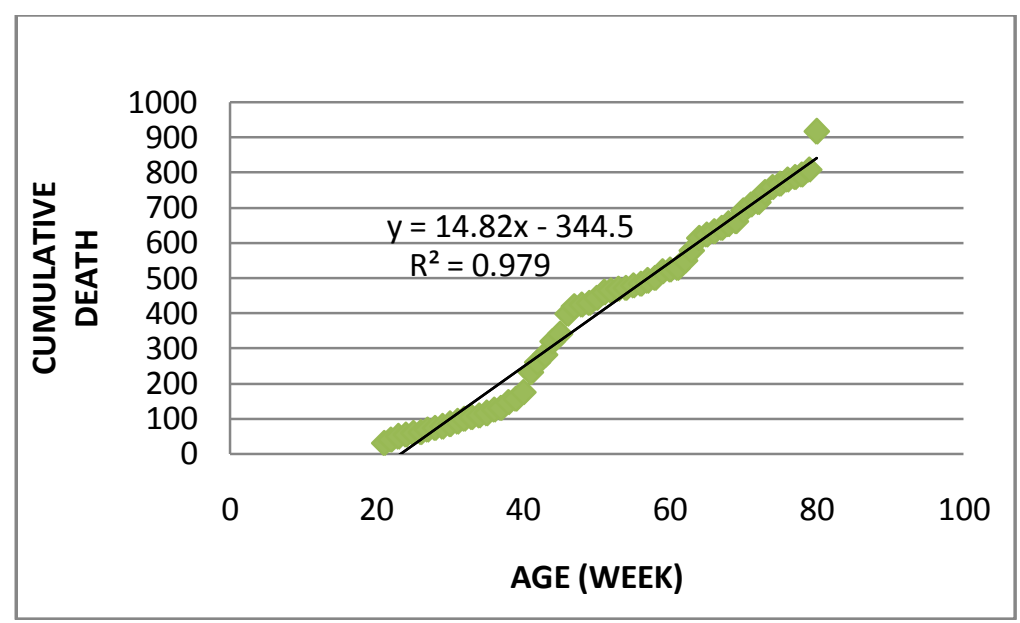

Fig 5. Cumulative mortality/culling of hens

Cumulative death/culling: Fig 5 denotes the cumulative death/culling of hens plotted against age of hens in week. It interpretes that in a 10000 hen-housed flock 14.82 dead/culled birds are added in each week with number of birds died/culled until previous week. The reason of death/culling was not available in the records. In an infectious-disease-free flock cannibalism and vent pecking might be the major cause of death/culling.No literature was found to compare this finding. However, in a large flock under normal condition death/culling rate could be guessed from this curve.

\section{References}

[1]. Amin, M.R. 2012. Incipient production efficiency of Babcock-380 layers in a control house in Kelantan. J bioentrepreneurship 2: 22-27.

[2]. Amin, M.R. and Hamidi, E.N. 2013. Effect of phytase supplementation on the performance of Babcock-380 layers. J tropical resource and sustainable science 1(1):36-41.

[3]. Anonym1 2013. Strain responses of laying hens to varying energy level. www2.ju.edu.jo....accessed on 2013.

[4]. Atta, M., Eljack, B.H. and El Obied, A.A. 2010. Use of mathematical modeling to evaluate production performance of some commercial layer strains under Khartoum State conditions (Sudan) Animal science Journal 1(1): 19-22.

[5]. Chowdhury, S.R., Chowdhury, S.D. and Smith, T.K. 2002. Effect of dietary garlic on cholesterol metabolism in laying hens. Poultry Science 81 (12):1856-1862.

[6]. Durrani, M.F. 2012. Egg production performance of commercial layers in Chakwal, Pakistan. Eprints.hec.gov.pk/460/1/347.html.htm. accessed on 12/12/2012.

[7]. Kaps, M. and Lamberson, W. 2009. Fixed effect one-way analysis of variance. In: Biostatistics for animal science. Cabi. pp 231271.

[8]. Singh, R, Cheng, K. M. and Silversides, F.G 2009. Production performance and egg quality of four strains of laying hens kept in conventional cages and floor pens. Poultry science 88:256-264.

[9]. Singh, R.P. and Kumar, J. 1994. Biometrical methods in poultry breeding (First edi.). Kalyani publishers, India. pp

[10]. Silversides, F.G., Singh, R., Cheng, K.M. and Korver, D.R. 2012. Comparison of bones of 4 strains of laying hens kept in conventional cages and floor pens. Poultry Science 91(1):1-7.

[11]. Verma, I.C. and Singh, K.S. 1997. Cost and return structure in layer farming. Indian J. Poultry science 32 (2):152-158. 